\title{
Domestic violence against women: representations of health professionals $^{1}$
}

\author{
Vera Lúcia de Oliveira Gomes² \\ Camila Daiane Silva ${ }^{3}$ \\ Denize Cristina de Oliveira ${ }^{4}$ \\ Daniele Ferreira Acosta ${ }^{5}$ \\ Cristiane Lopes Amarijo ${ }^{6}$
}

Objective: to analyze the representations about domestic violence against women, among health professionals of Family Health Units. Method: qualitative study based on the Theory of Social Representations. Data were collected by means of evocations and interviews, treating them in the Ensemble de Programmes Pemettant L'Analyse des Evocations software - EVOC and content analysis. Results: nurses, physicians, nursing technicians and community health agents participated. The evocations were answered by 201 professionals and, of these, 64 were interviewed. The central core of this representation, comprised by the terms "aggression", "physical-aggression", "cowardice" and "lack of respect", which have negative connotations and were cited by interviewees. In the contrast zone, comprised by the terms "abuse", "abuse-power", "pain", "humiliation", "impunity", "suffering", "sadness" and "violence", two subgroups were identified. The first periphery contains the terms "fear", evoked most often, followed by "revolt", "low self-esteem" and "submission", and in the second periphery "acceptance" and "professional support". Conclusion: this is a structured representation since it contains conceptual, imagetic and attitudinal elements. The subgroups were comprised by professionals working in the rural area and by those who had completed their professional training course in or after 2004. These presented a representation of violence different from the representation of the general group, although all demonstrated a negative connotation of this phenomenon.

Descriptors: Violence; Domestic Violence; Battered Women; Family Health; Professional Practice; Nursing.

\footnotetext{
${ }_{1}^{1}$ Supported by Conselho Nacional de Desenvolvimento Científico e Tecnológico (CNPq), Brazil, process \# $032 / 2012$.

2 PhD, Full Professor, Universidade Federal do Rio Grande, Rio Grande, RS, Brazil.

3 Doctoral student, Universidade Federal do Rio Grande, Rio Grande, RS, Brazil. Scholarship holder from Coordenação de Aperfeiçoamento de Pessoal de Nível Superior (CAPES), Brazil.

4 PhD, Full Professor, Universidade do Estado do Rio de Janeiro, Rio de Janeiro, RJ, Brazil.

${ }^{5}$ Doctoral student, Universidade Federal do Rio Grande, Rio Grande, RS, Brazil. Scholarship holder from Fundação de Amparo à Pesquisa do Estado do Rio Grande do Sul (FAPERGS), Brazil.

6 Master's student, Universidade Federal do Rio Grande, Rio Grande, RS, Brazil. Scholarship holder from Coordenação de Aperfeiçoamento de Pessoal de Nível Superior (CAPES), Brazil.
}

Corresponding Author:

Vera Lúcia de Oliveira Gomes

Universidade Federal do Rio Grande. Escola de Enfermagem

Rua Visconde de Paranaguá, 102, $3^{\circ}$ andar

Centro

CEP: 96203-900, Rio Grande, RS, Brasil

E-mail: vlogomes@terra.com.br
Copyright $\odot 2015$ Revista Latino-Americana de Enfermagem This is an Open Access article distributed under the terms of the Creative Commons Attribution Non-Commercial License (CC BY-NC).

This license lets others distribute, remix, tweak, and build upon your work non-commercially, and although their new works must also acknowledge you and be non-commercial, they don't have to license their derivative works on the same terms. 


\section{Introduction}

Universal problem, regardless of culture, education level, religion, financial status of those involved and the country's level of development, violence against women has been identified as a serious public health problem ${ }^{(1-3)}$. Researches carried out in developed and developing countries point its epidemic proportions and the impact that it triggers in the quality of life of the victims, families and society ${ }^{(3-5)}$.

The World Health Organization reveals that violence committed by an intimate partner is the most frequent, affecting about $30 \%$ of women ${ }^{(4)}$. On the world scene of violence, outlined between 2006 and 2010, El Salvador was in the first place with 10.3 femicides, and Brazil in the seventh with 4.4 in 100,000 women(5). Compulsory notifications performed in Brazil, between January 2000 and November 2010, show that 43,500 women were murdered. Of these cases, $68.8 \%$ occurred at home and the intimate partner was responsible for $65 \%$ of deaths in women aged between 20 and 49. In addition, every day, 38,020 women are assaulted in Brazil and, of these, $71 \%$ live with the aggressor and $66.5 \%$ do not financially depend on him( ${ }^{(6)}$.

Health services are often the first place to assist the victims and are important to detect the problem ${ }^{(7-8)}$. However, in practice, there are many beliefs, myths and representations that hinder or prevent the recognition and approach to domestic violence with female users, as many of them omit it, for fear or shame(9). To break the silence, it is believed that teams of the "Health Strategy for the Family, by means of the comprehensive coverage and bond"(7) established with families, can be effective allies. Such teams work both in the Family Health Unit (FHU), as in the residences, where they know the intimacy of homes, facilitating the recognition and taking of measures in cases of Domestic Violence Against Women (DVAW) ${ }^{(7)}$.

It is known that social representation of individuals or groups can reconstitute the reality confronted by them and for which they assign a specific meaning(9). Based on that, it was decided to investigate the representations of domestic violence against women of the professionals integrating health teams of the Family Health Units of the municipality of Rio Grande in the state of Rio Grande do Sul, Brazil, aiming to analyze such social representations as general purpose.

\section{Method}

This is a qualitative and descriptive study based on the theory of social representations carried out with health professionals of 19 FHUs, with 12 in the urban area and seven in the rural area, in the municipality of Rio Grande, in the state of Rio Grande do Sul, Brazil. It is emphasized that, the team of a Health Basic Unit (HBU) of the urban area declined the invitation, due to lack of time. In the 20 FHUs of the municipality worked, between July and November 2013, during the data collection, 29 nurses (N), 40 nursing technicians (NT), 24 physicians ( $P$ ) and 178 community health agents $(\mathrm{CHA})$, totaling 271 potential research participants.

The collection was carried out by means of free evocations and interviews. For the evocations, it was adopted as inclusion criteria: all professionals who agreed to participate in the research by signing the Consent Form. As exclusion criteria: professionals who were on sick leave, vacation or had rejected the invitation. Thereby, 201 professionals participated in the evocations. Participants were requested to evoke five words or phrases against the inductor term "domestic violence against women". The choice of the evocations is based on the possibility of apprehend the perception of reality, from a pre-existing semantic composition, which is concrete, imagetic and organized around few simple symbolic elements ${ }^{(9)}$.

Regarding data collection, through interviews, there is a consensus among the theorists of social representations that 30 is the minimum quantity to recover the representations of a group ${ }^{(10)}$. However, due to the large distance between the FHUs, as well as possible influence of the rural and urban areas in the representations of the respondants, it was decided to draw a map of the distribution of the units. Five regions were identified with 12 units in the urban area and six regions with seven units in the rural area. It is believed that proximity leads to a closer interaction between users and groups, resulting in similar social representations and accordingly, it was decided to raffle one FHU of each delineated area, for carrying out the interviews. Among the selected ones, it was invited to participate in this study, in a non-probabilistic mode and for convenience, at least, a doctor, a nurse, a NT and two $\mathrm{CHA}$, totaling 64 respondants.

For the interviews, a script was prepared by the researcher with open questions, which was tested in one of the non-selected units, for this methodological step. The interviews were carried out by a Master's student, in the own unit, in a room located far from the areas with large movement of persons and with average duration of 40 minutes. 
For data analysis, evocations were submitted to the Ensemble de Programmes Pemettant L'Analyse des Evocations software, EVOC 2005. The product resulting from this submission is a chart of four quadrants, based on the frequency and order of evocation of each word. It is noteworthy that, each quadrant contains essential information for the analysis of the representation under study. This chart is comprised by a central core, situated in the upper left quadrant which represents the most stable element of each representation and constitued by the words most frequently and promptly evoked(11). In the upper and lower right quadrants are the elements of the first and second peripheries, respectively. The lower left quadrant contains the contrast elements ${ }^{(11)}$.

It was used the content analysis proposed by $\operatorname{Bardin}^{(12)}$, for treating the interviews. According to this author, a "context unit serves as understanding unit to encode the registration unit and corresponds to the message segment whose dimensions (superior to those of registration unit) are optimal to understand the exact meaning of the registration unit"(12). Thus, it was selected few sentences containing words that compose the chart of four quadrants, showing the context in which interweers employed them. These sentences were identified by the letters $\mathrm{P}, \mathrm{N}, \mathrm{NT}$ and $\mathrm{CHA}$, which correspond to the initials of the professional category of respondants.

The Ethics Committee of the Federal University of Rio Grande approved the project, under Opinion number 020/2013.

\section{Results}

Of the 201 professionals who participated in the evocations, 26 were nurses, 21 physicians, 39 NT and 115 CHA. In the interviews, 64 professionals participated, of which 13 were nurses, 12 physicians, 12 NT and 27 CHA. In the FHUs of the urban area worked 146 professionals and 55 in the rural area. The average working time was five years and six months; the oldest employee had 17 years of service and the most recently hired employee had less than a year of service. Regarding the time of completion of professional training course, 112 have finished it before 2004 and, 89, in 2004, or after this year. As for marital status, 58 had no steady partner, 135 were living with a partner and eight had partner, but they were not living together. Participated in any event organized at the FHU, concerning to the violence against women, 147 respondants.

Interviewees evoked 1002 words, and of these, 252 were different. The chart of four quadrants is composed by the distribution of evoked words, considering the highest frequencies and average evocation orders (AEO) as criteria(11). In this study, it was adopted a minimum frequency of 12 , average frequency of 24 and AEO of 3 (Figure 1).

Given that, concept, image and attitude are forming dimensions of a social representation ${ }^{(13)}$, it was decided to analyze the presence of such attributes in the central core of this representation. It is worth mentioning that, in the central core are the most significant words for respondents. It contains the most consensual and stable part of the representation, consequently less sensitive to changes, depending on the external environment or the daily practices of subjects(11).

In this quadrant, the words "aggression" and "physical aggression" express the concept that respondants had about DVAW. In addition, the term "physical aggression" is associated with the image of the violent act or the marks left on the victim's body. The judgment made by professionals on the aggressor's actions was verbalized by the terms "cowardice", the most readily evoked, and "lack of respect". Accordingly, this is a structured representation, whose central core contains concept, image and judgment or attitude of respondents. This is a representation with negative connotation, which contains both aspects related to the practice of violent act, as the aggressor. Aiming to contextualize these terms, excerpts from the interviews in which they were employed are shown.

For me, the most serious assault was that he induced her to use drugs. Afterwards he assaulted her physically, verbally, and left her alone. He took the bus and left, but they both were not from here. He left and she was alone without any money, without her belongings. He was the partner. They were already living together. (NT)

The VDCM is a cowardice against women's rights as a person, as they usually have a reaction of less than man does. He has stronger physical vigor and more strength while she is more fragile. It is an act of cowardice unforgivable. $(\mathrm{P})$

Cowardice of the man, ignorance of the woman and lack of structure of the community to protect women. (N)

In the lower left quadrant is the contrast area, constituted by the most readily evoked words, however, with low frequency ${ }^{(11)}$. In this study, these words maintain the negative connotation of the representation of the DVAW and contain elements loaded with feelings and judgment. The contrast elements of this representation qualify the violent acts committed by the aggressor, identifying them as abuse and abuse of power. On the other hand, they refer to both feelings triggered in the victims, as in the professionals. 


\begin{tabular}{|c|c|c|c|c|c|c|}
\hline \multirow{2}{*}{$\begin{array}{c}\text { AEO* }^{*} \\
\text { Average Frequency }\end{array}$} & \multicolumn{3}{|c|}{$<3$} & \multicolumn{3}{|c|}{$\geq 3$} \\
\hline & Evoked term & Freq. & AEO & Evoked term & Freq. & AEO* \\
\hline \multirow{4}{*}{$\geq 24$} & Aggression & 43 & 1.907 & Low self-esteem & 26 & 3.423 \\
\hline & Physical- aggression & 26 & 2.269 & Fear & 43 & 3.186 \\
\hline & Cowardice & 34 & 1.794 & Revolt & 26 & 3.038 \\
\hline & Lack of respect & 36 & 2.500 & Submission & 25 & 3.280 \\
\hline \multirow{8}{*}{$<24$} & Abuse & 22 & 2.227 & Acceptance & 12 & 3.667 \\
\hline & Abuse of power & 20 & 2.800 & Professional support & 15 & 3.933 \\
\hline & Pain & 15 & 2.333 & & & \\
\hline & Humiliation & 16 & 2.938 & & & \\
\hline & Impunity & 19 & 2.895 & & & \\
\hline & Suffering & 16 & 2.688 & & & \\
\hline & Sadness & 21 & 2.762 & & & \\
\hline & Violence & 13 & 2.692 & & & \\
\hline
\end{tabular}

*Average Evocation Orders

Figure 1 - Chart of four quadrants of the social representation about domestic violence against women, among health professionals of FHUs of the municipality of Rio Grande, RS, Brazil, 2013

I think violence is abuse, it is aggression, it is unloving, lack of self-esteem of the woman, that's it. (NT)

For me it's much humiliation. A woman undergoes much humiliation, much submission, sometimes she is, largely dependent on the husband, so it is a terrible thing to depend and at the same time be hit by the same person, it is quite complicated. (CHA)

My reaction is sadness. Because they do not have maturity to talk, keep calm when bad things are happening, they fought like that. It's very unpleasant, very sad. (NT)

It is noteworthy that, the contrast zone can contains elements that show variations of representation in terms of subgroups, without changing the core elements and the representation itself(11). Thus, it is worth mentioning that the terms "impunity" and "sadness", present in the contrast zone of the overall chart, constitute the central core of the chart of four quadrants of the professionals working in the rural area, showing that this subgroup had a representation different from the others. This finding allows inferring that these professionals want effective punitive measures, besides expressing with the term "sadness", the affective dimension that permeates this representation.

When I talk about impunity and abandonment, this is what she reported. She is protected by the Maria da Penha Law, sheltered in this halfway house and remains victim. She came to call for help, was matrixed by the Family Health Support Center (NASF), and we are completely powerless against reality, because this man is released and continues to offer danger. She has been to several public safety bodies where they had told her the best thing to do was to leave the city. He is a drug user, convict, he assaulted her physically and verbally. She had to leave this neighborhood, almost gave away her house and took refuge here. He came behind her and just broke into the house. It is the story of a woman saying that there will come a time that she will kill him or be killed by him. This makes us very distressed and sad because she has come all the legal proceedings, notified, has several police reports, and he's a bandit. She is scared. The family supports her, but it is a family of women, who are frightened because he is a bandit. ( $P$ )

When analyzing the representation of the DVAW, according to the professional training period, it is noticed that in the central core of the representations of professionals graduated in or after 2004, it is observed the term "abuse". This term, which integrates the contrast zone of the overall picture, shows a difference ${ }^{(11)}$ between the representation of this group and the totality of respondents.

In the first periphery of the representation, there are the words with high frequency and average position in the evocation order, not allowing them to integrate the central core ${ }^{(11)}$. In this study, such periphery is comprised by the terms "fear", evoked most frequently, followed by "revolt", "low self-esteem" and "submission".

Their greatest fear is to denounce the aggressor and stay in the house with him, so it is useless to report only, it is necessary to get her out of that place to facilitate this action. (P)

We are afraid to interfere, to guide, because we know it happens once ... then soon it is over! The couple fight and on the following day, everything is back to normal. Then, during a conversation they say: Ah! If I had listened to what they tell me, I had denounced you .. When you realize, you are worried because you have interfered. It is wrong, but much we hide, listen and keep, because we are also afraid of exposure. (NT)

The first thing they tell you: Please, don't tell anyone, for God's sake! I'm gonna tell you, but if you tell anyone, I'm 
gonna say you are lying. Of course, I am not going to spread it. I cannot even do this. It's very complicated. It's a situation about which there is nothing, nothing we can do. We keep hoping, but then we go to her house and she has a black eye. We will not be able to do much. It's very, very revolting, not to be able to do anything. It is quite complicated. (CHA)

I feel revolt, because I think it's very unfair to a woman suffering any kind of violence. Even for the woman who works the whole month and her husband is who dictates how the money you will be spent. I've seen colleagues who received their salaries and had to give the money on their husband's hand. He decided what he had and what he had not to pay; in what he had and what he had not to spend. I think it's horrible because the woman is a human being as man and has equal rights and wills. ( $\mathrm{CHA}$ )

In the right lower quadrant there are the terms with low frequency and low evocation order, forming the second periphery, which constitutes the interface that better matches the social practices representation ${ }^{(11)}$. The terms "acceptance" and "professional support", which compose it, were not mentioned literally by the respondents, but their meaning are expressed in the context.

First, we receive the woman and let her to vent and say what she's feeling, and then we try to do the clinical examination and seek the available support networks to help this woman. We try to follow both the ethical professional point of view, as what we have by law. When we are receiving and listening to this person, we try not to stand, be critical or guide the life of that person who is asking you for help. (N)

\section{Discussion}

The central core of a social representation constitutes the most stable and consensual element ${ }^{(11)}$. The concomitant presence of the terms "aggression" and "physical aggression" in the central core can indicate that respondents, in addition to physical violence, included in their representations other forms of violence described in the Maria da Penha Law, ie, psychological, patrimonial, sexual and moral(14). Regarding these forms of violence, a study identified the occurrence of threats, humiliation, intimidation, insult, kicking, throwing objects, shoving, forced sex with their partners, among others ${ }^{(15)}$.

The term "fear", which appears in the first periphery, has two interpretations. It can refer to the feeling of the victim against the aggressor, as well as to the own professionals who are afraid to get involved, or involve the family with violent customers. The fear of retaliation is expressed in a study that addresses the subnotification of the DVAW, emphasizing that to give visibility to this crime can lead to harmful consequences for both the users, as for professionals ${ }^{(16)}$. The powerlessness and the fear of health professionals in relation to the DVAW have also been published by other researchers ${ }^{(8,17)}$. This situation can lead to feelings of revolt, low self-esteem and submission in both.

Unlike fear, which is a negative feeling and often, immobilizer, revolt is a positive feeling and can be a precursor of coping, ie, an action that allows minimizing or solving the problem. From the 80 's, a movement of revolt was triggered, leading women to rebel against impunity for crimes committed under the allegation of legitimate defense of honor. They claimed public security policies and justice. This movement triggered the promulgation of the Law 11.340/2006, known as Maria da Penha Law ${ }^{(14)}$, which increased the stringency of punishments and enabled the creation of programmes for rehabilitation and recovery of aggressors, as well as services of protection to victims ${ }^{(14)}$.

The words "submission" and "low self-esteem" are also negative because they lead to inactivity. In this sense, the biopharmaceutical Maria da Penha, while celebrating six years of the law that bears her name, said that it is easier for women to react in the first aggression attempts. After being subjected to constraint for a long period, they stop denouncing, because their "self-esteem disappears", and this passivity can lead to the trivialisation of domestic violence(6). A phenomenological study adds by pointing the need to overcome the natural attitudes by questioning about "social knowledge inherited and reproduced that lead to such unequal relationships between men and women, which culminates in violent acts"(2) and are often precursors of intergenerational reproduction of violence.

The terms "acceptance" and "professional support" demonstrate the interface of the representation of the DVAW with the social practice of respondents(7). Considering the complexity of the problem, they mentioned to seek support in the multidisciplinary team of the Support for Family Health Center (NASF), in an attempt to obtain a better resolution. On the other hand, a study carried out in São Paulo describes the limitations of NASF due its bond to various FHUs, which prevents it to meeting demand(7). In addition, other research denounces the lack of aticulation between the services, warning that this problem needs to be overcome, as there is a range of services working alone. When there is articulation, "it occurs by specific and personal initiatives, however is not observed an integrated and referenced 
network for attention to these cases"(8). In addition, a study carried out with nurses and physicians revealed that they listed as facilitators to assisting the victims, access to colleagues for consultation, participation in a multidisciplinary team and support from other services such as social assistance ${ }^{(18)}$.

The contrast zone contains terms that can reinforce both the first periphery, as expressing a diverse thinking within the group or subgroup with differentiated representation ${ }^{(11)}$. In this study, the subgroups composed by professionals working in the rural area and those who have completed their professional training course in or after 2004, show a representation of the DVAW different from the whole group. In this study, the contrast zone maintains its negative connotation and contains elements loaded of feelings and judgments.

The contrast elements of this representation reinforce the central core, judging the acts of the aggressor and qualifying them as abuse and abuse of power. On the other hand, they also refer to the feelings that violence triggers on the victims, such as sadness, humiliation, suffering and pain, which are consistent with the first periphery. The term "impunity", contained in the contrast zone, can express the omission of respondents from a legal point of view; in this sense, it is pointed out that the belief in impunity can be supportive of the perpetuation of violence, by discouraging coping(2).

Accordingly, as coping strategies of the DVAW, recent studies have shown as essential, the preparation of professionals to detect cases, as well as the need for coordinated multidisciplinary teams and network performance, since isolated initiatives are inefficient ${ }^{(18-20)}$. They also point out undernotification as an obstacle to assessing the magnitude of the problem and designing strategies that lead to solving ${ }^{(8,16)}$.

\section{Conclusion}

The analysis of social representations about DVAW, among health professionals working in FHUs of the municipality of Rio Grande, showed that this is a representation with a negative and structured connotation, because it contains conceptual, imagetic and attitudinal elements.

Another important aspect identified was the presence of subgroups constituted by professionals working in the rural zone, and who have completed their professional training course in or after 2004, with a representation of the DVAW that differs from the representation of the general group, even though they showed a negative connotation about the phenomenon.

Based on the representations apprehended, a round table discussion with authorities on the subject was carried out to discuss together with professionals of the FHUs and nursing students, aspects related to obligatory notification, professional ethics code and Maria da Penha Law, juridical, ethical and legal implications of assistance to victims and potential and necessary referrals. Strategies like this help in detecting, combating and preventing DVAW and must be reproduced in the meetings of the family health teams, hospital environment and among academics of health areas.

\section{References}

1. Moura MAV, Albuquerque Netto L, Souza MHN. [Sociodemographic profile for women who faces the violence and get the support at specialized police stations]. Esc Anna Nery. 2012;16(3):435-42.

2. Vieira LB, Padoin SMM, Oliveira IES, Paula CC. [Intentionalities of women who decide to denounce situations of violence]. Acta Paul Enferm. 2012;25(3):423-9.

3. Reichenheim ME, Souza ER, Moraes CL, Mello Jorge MHP, Silva CMFP, Minayo MCS. [Violence and injuries in Brazil: the effect, progress made, and challenges ahead]. The Lancet. 2011;377(9781):1962-75.

4. World Health Organization. Report highlights violence against women as a 'global health problem of epidemic proportions'. WHO [Internet]. 2013. [acesso 14 out 2013]. Disponível em: http://www.who.int/ mediacentre/news/releases/2013/violence_against_ women_20130620/en/index.html

5. Waiselfisz J]. [Map of Violence 2012. The new patterns of homicidal violence in Brazil]. São Paulo. Instituto Sangari; 2011.

6. Secretaria de Política para as Mulheres (BR). Balanço da central de atendimento à Mulher. [Internet]. [acesso 11 mar 2014]. Brasília: Editora do Ministério da Saúde; 2010. Disponível em: http://www.sepm.gov.br/notícias/ últimas_notícias/2010/10/balanço-da-centra-deatendimento-a-mulher.

7. Gomes NP, Erdmann AL. [Conjugal violence in the perspective of "Family Health Strategy" professionals: a public health problem and the need to provide care for the women]. Rev. Latino-Am. Enfermagem. 2014;22(1):76-84.

8. Guedes RN, Fonseca RMGS, Egry EY. [The evaluative limits and possibilities in the Family health strategy 
for gender-based violence]. Rev Esc Enferm USP. 2013;47(2):304-11.

9. Silva LA, Gomes AMT, Oliveira DC, Souza MGG. [Social representations of aging in institutionalized psychiatric patients]. Esc Anna Nery. 2011;15(1):124-31.

10. Santos EI, Gomes AMT, Oliveira DC. [Representations of vulnerability and empowerment of nurses in the context of HIV/AIDS]. Texto Contexto Enferm. 2014;23(2):408-16. Portuguese.

11. Oliveira DC, Gomes AMT, Acioli S, Sá CP. [The Brazilian health care system in the mental cartography of health professionals]. Texto Contexto Enferm. 2007;16(3):377-86.

12. Caregnato RCA, Mutti R. [Qualitative research: discourse analysis versus content analysis]. Texto Contexto Enferm. 2006;15(4):679-84. Portuguese.

13 Paschoal EP, Espírito Santo CC, Gomes AMT, Santos EI, Oliveira DC, Pontes APM. [Adherence to antiretroviral therapy and its representations for people living with HIV/ AIDS]. Esc Anna Nery. 2014;18(1):32-40. Portuguese. 14. Brasil. [Law n. 11,340 of August 7, 2006. Maria da Penha Law]. Câmara dos deputados, Coordenação de Publicações [Internet]. 2007 [acesso 2 set 2011]. Disponível em: http://www.cepal.org/oig/doc/ Bra2006Leimariadapenha.pdf. Portuguese.

15. Abeya SG, Afework MF, Yalew AW. Intimate partner violence against women in western Ethiopia: prevalence, patterns, and associated factors. BMC Public Health. [Internet]. 2011;11:913 [acesso 25 ago 2014]. Disponível em: http://www.ncbi.nlm.nih.gov/pmc/ articles/PMC3252295/

16. Kind L, Orsini MLP, Nepomuceno V, Gonçalves L, Souza GA, Ferreira MFF. [Primary healthcare and underreporting and (in)visibility of violence against women]. Cad Saúde Pública. 2013;29(9):1805-15. Portuguese.

17. D'Oliveira AFPL, Schraiber LB, Hanada HDJ. [Comprehensive health (care) services to women in gender violence situation: an alternative to primary health care]. Ciênc Saúde Coletiva. 2009;14(4):103750. Portuguese.

18. Beynon CE, Gutmanis IA, Tutty LM, Wathen CN, MacMillan HL. Why physicians and nurses ask (or don't) about partner violence: qualitative analysis. BMC Public Health. [Internet]. 2012;12:473. [acesso 26 ago 2014]. Disponível em: http://www.ncbi.nlm.nih.gov/pmc/ articles/PMC3444396/

19. Ali TS, Asad N, Mogren I, Krantz G. Intimate partner violence in urban Pakistan: prevalence, frequency, and risk factors. Int J Womens Health. [Internet]. 2011;3:105-
15. [acesso 26 ago 2014]. Disponível em: http://www. ncbi.nlm.nih.gov/pmc/articles/PMC3089428/

20. Garcia-Moreno C. Dilemmas and opportunities for an appropriate health-service response to violence against women. Lancet. [Internet]. 2002 Apr 27 [acesso 24 ago 2014];359(9316):1509-14. Disponível em: http:// www.thelancet.com/journals/lancet/article/PIIS01406736(02)08417-9/fulltext
Received: May 20 2014

Accepted: Dec $9^{\text {th }} 2014$ 